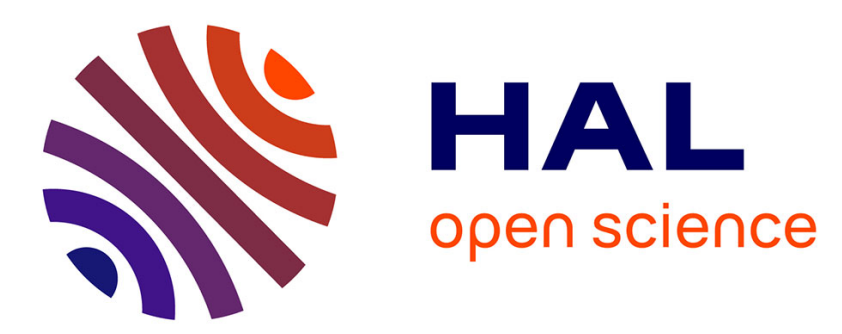

\title{
Choosing None of the Above: Persistence of Negativity after Group Discussion and Group Decision Refusal
}

\author{
Bernard A. Nijstad
}

\section{To cite this version:}

Bernard A. Nijstad. Choosing None of the Above: Persistence of Negativity after Group Discussion and Group Decision Refusal. Group Processes and Intergroup Relations, 2008, 11 (4), pp.525-538. 10.1177/1368430208095404. hal-00571703

\section{HAL Id: hal-00571703 \\ https://hal.science/hal-00571703}

Submitted on 1 Mar 2011

HAL is a multi-disciplinary open access archive for the deposit and dissemination of scientific research documents, whether they are published or not. The documents may come from teaching and research institutions in France or abroad, or from public or private research centers.
L'archive ouverte pluridisciplinaire $\mathbf{H A L}$, est destinée au dépôt et à la diffusion de documents scientifiques de niveau recherche, publiés ou non, émanant des établissements d'enseignement et de recherche français ou étrangers, des laboratoires publics ou privés. 


\title{
Choosing None of the Above: Persistence of Negativity after Group Discussion and Group Decision Refusal
}

\author{
Bernard A. Nijstad \\ University of Amsterdam
}

\begin{abstract}
Within psychology and other disciplines, group decision making is a much-studied topic. However, the conditions in which groups do not decide but rather refuse to choose among available options have not been studied systematically. This research begins to fill this void, studying the effects of the initial opinions of group members on group decision refusal. Based on the common knowledge effect, it is predicted and found that groups will often refuse all available options when group members are initially negative about the options. It is further found that, when initial opinions are negative, positive information entered during group discussion does not have much impact. The implications of this negativity bias are discussed.
\end{abstract}

KEYWORDS common knowledge effect, decision refusal, group decision making

MANY important decisions are made in groups. Indeed, collective decision making has two important advantages over individual decision making. First, because a group of people in general will have more information available to it than any of its members separately, groups have the potential to make a better choice. Second, group decisions might yield greater acceptance than individual decisions, which can have the advantage that people are more committed to the decision (Stasser \& Titus, 1985; Vroom \& Yetton, 1973). Group decision making has therefore long been a topic for psychological research (for a recent review, see Kerr \& Tindale, 2004).

Despite this long tradition of psychological research, one topic has received limited attention. This is the topic of group decisions that do not get made. In the typical group decision-making study, groups simply have to make a choice among the available alternatives, because a "no choice' option is not available. One exception is mock jury decisions, in which juries can be 'hung' when they do not reach agreement on a verdict. There has been some interest in predicting when juries will be hung (Kerr \& MacCoun, 1985). However, in many other real life decisions, it often is possible to refuse making decisions

\footnotetext{
Author's note

Address correspondence to Bernard Nijstad, University of Amsterdam, Department of Work and Organizational Psychology, Roetersstraat 15, 1018 WB Amsterdam, The Netherlands [email: b.a.nijstad@uva.nl]
} 
as well. Indeed, common experience suggests that meetings can drag on forever without any decisions being made, that decisions are often deferred to later meetings, that groups refuse to commit themselves to a chosen alternative, or that groups appoint committees to 'investigate the need for further investigation'. As far as I know, these topics have not been the subject of systematic research.

In this article, I begin to study group decisions that do not get made. In particular, I focus on one type of indecision, which Corbin (1980) has called 'decision refusal'. In the case of group decision refusal, all currently available alternatives are rejected, and instead the group decides to invest further resources to look for more alternatives. I argue that decision refusal in groups becomes likely when group members enter the discussion with a negative view on all available options. I further argue that this negative view is likely to persist even after positive information becomes available during discussion. As a consequence, groups will often refuse to choose, even though the decision options might be perceived as adequate had all information been known from the beginning.

\section{Decision refusal in groups}

\section{Decision refusal}

Corbin (1980) has provided a theoretical framework to think about decisions that do not get made. She argued that in different stages of the decision process different forms of not deciding occur. In the early stages, a decision opportunity might not be identified as such and the decision processes will consequently not be started. Corbin calls this inattention. In the middle stages, when decision makers are evaluating the available alternatives, decision makers may delay their decision. According to Corbin, delay occurs when decision makers are uncertain about which of the alternatives they prefer, for example, because alternatives are close in attractiveness (also see Dhar, 1997; Tversky \& Shafir, 1992). Decisions consequently are delayed in order to resolve preference uncertainty (e.g. by searching for more information about the available options). Finally, in the end stages of a decision, a decision maker may think that none of the available alternatives is sufficiently attractive, which may lead to refusal of all available options (and therefore to no choice being made). Rather than trying to establish which of the currently available alternatives is best, the decision maker rejects all available alternatives and decides to invest resources to identify more alternatives (e.g. go to a different store to look at more products, interview more job candidates).

In the present article, the focus is on decision refusal in groups, addressing the question: When will groups refuse all available options, and rather decide to invest further resources to identify more options? This question is highly relevant, because in many decision situations initial choice sets are incomplete, which offers the possibility to identify more options. Decision refusal is not by definition a maladaptive response. Indeed, if all currently available options are unattractive, it might be better to look for more options. However, there is a point after which the investments in the search for more options will no longer pay off. Thus, adaptive decision making should depend on the balance between the costs of searching and the potential benefits of finding a superior alternative (also see Tversky \& Shafir, 1992), and refusal is maladaptive when adequate alternatives are rejected while search costs are high. It should further be noted that decision refusal is not the same as choosing the status quo. When choosing the status quo, the decision process is ended, whereas when refusing all currently available options the decision process is extended and resources are used to search for further alternatives.

\section{Social decision schemes, information sharing and decision refusal}

Previous work on mock jury decisions suggests that juries can be hung, implying that no decision is reached, when there are opposing factions who do not give in. Kerr and MacCoun (1985), for example, manipulated jury size, polling method (public or private) and closeness of the case. They found that public polling led to more hung juries, especially when juries were large and cases were close. In larger juries and 
with closer cases there is a higher likelihood that jurors hold different opinions (i.e. some favour guilty, other favour not guilty). With public polling methods, jurors are less likely to give in, because they feel more committed to their original verdict, leading to more hung juries. Thus, it seems that preference diversity might be one antecedent of group indecision, especially if group members are not likely to concede to others (also see Nijstad \& Kaps, 2008).

However, to complement this picture, in this article I derive another prediction on when groups might refuse to choose. This prediction is based on social decision scheme (SDS) theory (Davis, 1973), and work on collective information sampling and the common knowledge effect (Gigone \& Hastie, 1993, 1997; Larson, Foster-Fishman, \& Keys, 1994; Stasser \& Titus, $1985,1987)$. To derive these predictions, it is assumed that decisions refusal is an additional choice option (e.g. choose A, choose B, or refuse both $A$ and $B$ ) that will be taken when all other available options are judged to be insufficiently attractive (cf. Anderson, 2003; Corbin, 1980; Dhar, 1996).

SDS theory models group decisions with two parameters, preference distributions and social decision schemes. Preference distributions reflect how many group members support each of the available alternatives. The SDS specifies the relation between these preference distributions and group decisions. For example, with a 'majority wins' SDS, the group would choose option A when at least a majority of group members favours A. Indeed, one of the most robust findings in group decision-making research is that majority wins is a very dominant SDS, and is used in many decision-making groups (Stasser, 1999). Based on this, one would predict that a group chooses the refusal option when a majority of group members initially has a preference for decision refusal.

Groups that choose on the basis of a majority wins SDS will often do well: if most people independently prefer a certain option, it is likely to be a good option. However, groups can sometimes choose a suboptimal alternative as a consequence of using a majority wins SDS. This is the case in hidden profile situations (Stasser \&
Titus, 1985). In hidden profiles, group members before the discussion have some information in common with the other group members (shared information) and some information that is uniquely available to them (unshared information). Based on this incomplete set of information, each group member before discussion comes to prefer a certain alternative. However, they would recognize that alternative as suboptimal when all information is taken into account, because the unshared information points towards another alternative. Thus, only with a full exchange of (unshared) information during discussion will group members recognize that their initial preferences were incorrect. Unfortunately, much research has shown that group discussions are often biased towards shared information, that unshared information is discussed less, and that groups therefore often fail to discover the hidden profile (Larson et al., 1994; Stasser, Taylor, \& Hanna, 1989; Stasser \& Titus, 1985, 1987).

Further, even when information is fully discussed, groups often do not discover the hidden profile (Greitemeyer \& Schulz-Hardt, 2003; Postmes, Spears, \& Cihangir, 2001). The reason is that, after a preference is formed, new information that becomes available is evaluated in a biased way. Thus, Greitemeyer and Schulz-Hardt (2003) found that, in a hidden profile situation, preference-consistent information evaluation kept decision quality low despite a full exchange of information. This is one of the causes of the common knowledge effect: the effect that shared information has a bigger impact on choice than unshared information (Gigone \& Hastie, 1993, 1997). Shared information first has a bigger impact on pre-discussion preferences, because by definition it is available to all group members and thus has an impact on each group member's preference. Second, new information (i.e. unshared information) that comes up during group discussion is often evaluated in a biased way, so it does not have much impact on final choices.

Based on the common knowledge effect and SDS theory, one can make predictions on group decision refusal. It is possible to create biased information sets, in which negative information 
about decision options is shared, whereas all positive information is unshared. As a result, group members will come to the discussion with a negative view on all decision options, and a preference for decision refusal (i.e. take none of the options). During discussion, they fail to discuss unshared positive information, and if positive information is discussed, it does not have much impact on choice. Thus, groups will often take the refusal option when most members initially favour refusal (i.e. a majority wins SDS is applied). However, when all positive and negative information is be available to group members from the start, they will not take the refusal option.

\section{The present study}

In the present experiment, three ways of distributing information among group members were used to manipulate pre-discussion preferences for decision refusal. In all conditions, the group as a whole received the same information, but this was distributed in three different ways across group members. In condition 1 (full information), every group member received full information before discussion. This condition can be seen as a control condition, and can be used to see whether groups choose or refuse when full information is available from the start, and thus whether alternatives (given full information) are perceived to be adequate. In condition 2 (positive bias), group members received biased profiles, in which all group members received all the positive information about each alternative, but all negative information was unshared. This should create a relatively positive view on the alternatives before discussion. In condition 3 (negative bias) this was reversed, and all group members received all negative information before discussion, whereas positive information was unshared. This should create a negative view on the alternatives before the discussion.

The following predictions are tested. First, compared with the full information condition and the positive bias condition, group members will be more negative about the alternatives and will more often be in favour of decision refusal before the discussion (Hypothesis 1). Second, because in the positive bias condition positive information is shared and negative information unshared, whereas in the negative bias condition this is reversed, it is expected that more positive than negative information will be discussed in the positive bias condition and more negative than positive information in the negative bias condition (Hypothesis 2). In the full information condition, no systematic bias is expected. Third, because of more negative initial views and a bias in the discussion towards negative information (Hypothesis 1 and Hypothesis 2), more groups in the negative bias condition than in the other conditions will choose the refusal option (Hypothesis 3). The effect of condition on group choice will be mediated by pre-discussion preference distribution and information exchange (Hypothesis 4).

\section{Method}

\section{Participants}

Participants were 90 students (18 males and 66 females, 6 participants did not indicate their gender) of the University of Amsterdam, who participated in 30 three-person groups. They either received course credit or were paid $€ 7$ for their participation. The average age of the participants was 20.36 years old $(S D=2.35)$.

\section{Design and materials}

There were three conditions: a condition with complete information, a condition with positively biased information, and a condition with negatively biased information. Participants were randomly assigned to conditions and groups, with 10 groups in each condition. Conditions differed from each other only in the way information was distributed among the group members.

Participants had to decide among three female candidates who had applied for a teaching position at the department of psychology. Before the group discussion, they individually received information about the three candidates, consisting of information for each candidate on six attributes. These attributes were pre-tested for importance in a sample of 32 students from 
the same population as the main study. The six attributes, with average importance ratings $(1$, not important to 7 , very important) from the pre-test in parentheses, were: clarity (6.53), enthusiasm (6.31), patience (5.78), conscientiousness (5.66), teaching experience (4.53) and university grades (3.53). Each of the three candidates was given three positive (e.g. is very enthusiastic when teaching) and three negative attributes (e.g. has no teaching experience). These attributes were matched for importance, in such a way that the three candidates were approximately equally attractive.

The group as a whole always received the same (complete) information. However, I created three conditions by using three different ways of information distribution among the three group members (see Table 1). In condition 1, each group member received complete information about all the candidates (complete information condition). In condition 2 (positive bias condition), all positive information about the candidates was shared and was given to all group members. However, the negative information was unshared, and each piece of negative information was given to only one group member. In condition 3 (negative bias condition), this was reversed, so that all negative information was given to all group members, whereas positive information was unshared and given to only one group member.

\section{Procedure}

Participants were first seated individually, and read a general introduction. They had to imagine that they were member of a three-person selection committee that had to decide whom to hire for a teaching position at the department of psychology. They were told that there were three candidates, who had all finished their master's degree at a Dutch university. They had to decide, together with two other participants, whom to hire. However, they were told that it was also possible not to hire anybody, but to look for further candidates, and this was the refusal option. It was emphasized that they should only do this when they really thought that none of the current candidates was suitable for the position. They further read that, in real life, looking for further candidates is expensive and time-consuming. They were thus instructed to hire a candidate when they thought she was suitable, and only reject all candidates when they really thought that none of them was suitable for the job.

After this general instruction, participants individually received the candidate profiles. They had six minutes to study the profiles, and were told that they could not refer to these profiles during the later group discussion. They further read that it was possible that other group members had information different from their own. After six minutes, the experimenter collected

Table 1. Information distribution in the three conditions

\begin{tabular}{|c|c|c|c|c|}
\hline \multirow[b]{2}{*}{$\begin{array}{l}\text { Group } \\
\text { member }\end{array}$} & \multirow[b]{2}{*}{ Candidate } & \multicolumn{3}{|c|}{ Condition } \\
\hline & & $\begin{array}{l}\text { Complete information } \\
\text { (all information shared) }\end{array}$ & $\begin{array}{l}\text { Positive bias (negative } \\
\text { information unshared) }\end{array}$ & $\begin{array}{l}\text { Negative bias (positive } \\
\text { information unshared) }\end{array}$ \\
\hline \multirow[t]{3}{*}{1} & A & $1+, 2-, 3+, 4-, 5+, 6-$ & $1+, 2-, 3+, 5+$ & $2-, 4-, 5+, 6-$ \\
\hline & B & $1-, 2+, 3-, 4+, 5-, 6+$ & $2+, 4+, 5-, 6+$ & $1-, 2+, 3-, 5-$ \\
\hline & $\mathrm{C}$ & $1+, 2-, 3-, 4+, 5-, 6+$ & $1+, 3-, 4+, 6+$ & $1+, 2-, 3-, 5-$ \\
\hline \multirow[t]{3}{*}{2} & A & $1+, 2-, 3+, 4-, 5+, 6-$ & $1+, 3+, 4-, 5+$ & $2-, 3+, 4-, 6-$ \\
\hline & B & $1-, 2+, 3-, 4+, 5-, 6+$ & $2+, 3-, 4+, 6+$ & $1-, 3-, 4+, 5-$ \\
\hline & $\mathrm{C}$ & $1+, 2-, 3-, 4+, 5-, 6+$ & $1+, 2-, 4+, 6+$ & $2-, 3-, 5-, 6+$ \\
\hline \multirow[t]{3}{*}{3} & A & $1+, 2-, 3+, 4-, 5+, 6-$ & $1+, 3+, 5+, 6-$ & $1+, 2-, 4-, 6-$ \\
\hline & B & $1-, 2+, 3-, 4+, 5-, 6+$ & $1-, 2+, 4+, 6+$ & $1-, 3-, 5-, 6+$ \\
\hline & $\mathrm{C}$ & $1+, 2-, 3-, 4+, 5-, 6+$ & $1+, 4+, 5-, 6+$ & $2-, 3-, 4+, 5-$ \\
\hline
\end{tabular}

Note: 1 , clarity; 2 , enthusiasm; 3 , patience; 4 , conscientiousness; 5 , experience; 6 , grades. Positive information is indicated by + , negative information by - . For example, $1+$ means that the candidate scores high on the attribute 'clarity.' Unshared information is given in bold. 
the profiles and distributed a pre-discussion questionnaire. Participants were asked what their individual decision at that moment would be (hire candidate A, B or C, or not hire any candidate), and they were asked to rate each candidate's attractiveness.

Next, they received a follow-up instruction. They were told that they would participate in a group discussion, and that they should jointly decide whom to hire. It was repeated that they should hire a candidate when they thought she was suitable, but could also decide not to hire any of the candidates but look for further candidates. Again it was emphasized that this would cost additional time and money. They were next seated in one room, and were provided with a group decision sheet on which they could indicate their decision. All group discussions were videotaped. When the group had reached a decision, the participants were separated and individually filled out a post-experimental questionnaire. After that, they were debriefed, paid and dismissed.

\section{Dependent variables}

The main dependent variable was group choice, coded dichotomously as either choice (i.e. hire candidate A, B or C) or refusal (hire none of them, but look for further candidates).

For each group, group composition in terms of pre-discussion preferences was established, using the pre-discussion questionnaire. I distinguished between groups with no, one, two and three members in favour of refusal. In the prediscussion questionnaire, the three candidates were each also rated on three 7-point scales (1, completely disagree to 7 , completely agree) to assess suitability for the job (e.g. "candidate A would be a good teacher'). Cronbach's $\alpha$ for candidates A, B and C were .95, .92 and .94, respectively. Per candidate, the three items were therefore averaged in an index of job suitability.

Video recordings were coded for the exchange of information and the exchange of preferences. For each item of information that was available about the candidates, a coder who was blind to conditions and hypotheses coded whether or not it was mentioned during the discussion. Further, the coder tallied how often attractions for a certain candidate or aversions against a certain candidate were expressed. To establish intercoder reliability, a second coder independently coded the recordings of 10 groups. The coders agreed in $93.5 \%$ of the cases that a certain piece of information had been mentioned or not. The reliability of the number of times an attraction or aversion was expressed was established with the intraclass correlation, which was .81. Given these high reliabilities, the data from the first coder were used.

In the post-experimental questionnaire, participants were asked to give their own, individual preference after the discussion, as well as the degree to which they agreed with the group's choice. Two items were used (e.g. 'I agree with the group decision') and they were averaged into a measure of agreement (Cronbach's $\alpha=.85$ ). They were further asked to rate each candidate's suitability as a teacher, with the same items as in the pre-discussion questionnaire. Cronbach's $\alpha$ for candidates A, B and C respectively were .93, .92 and .95 . Finally, two items measured whether new information came up during discussion (e.g. 'others mentioned information that I did not have'), and Cronbach's $\alpha$ was .94. Before analysis, all post-discussion data was aggregated to the group level, by taking the average of the three group members.

\section{Results}

\section{Pre-discussion preferences and candidate ratings}

One-way analysis of variance (ANOVA) showed that information distribution reliably affected the number of group members in favour of refusal before the discussion, $F(2,27)=15.96$, $p<.001, \eta^{2}=.54$ (see Table 2). Not a single group member initially favoured refusal in the positive bias condition, and on average 0.40 of three members favoured refusal in the complete information condition. The negative bias condition differed reliably from both other conditions (Tukey post-hoc test, $p<.01$ ), with an average of 1.4 members per group preferring refusal before discussion. This resulted in the following preference distributions: in the full information condition, six groups had no group 
Table 2. Dependent variables by condition

\begin{tabular}{lccc}
\hline & & Condition & \\
\cline { 2 - 4 } Dependent variable & Full information & Positive bias & Negative bias \\
\hline $\begin{array}{l}\text { Pre-discussion refusal (No. group } \\
\quad \text { members) }\end{array}$ & $0.40^{\mathrm{a}}(.52)$ & $0.00^{\mathrm{a}}(.00)$ & $1.40^{\mathrm{b}}(.84)$ \\
Group refusal (\%) & $20 \%$ & $10 \%$ & $60 \%$ \\
Discussion time (min.) & $8.93(4.61)$ & $7.06(3.33)$ & $7.38(3.87)$ \\
Video recordings: & & & $6.60(2.01)$ \\
$\quad$ Positive items mentioned & $5.22(2.59)$ & $7.40(1.35)$ & $5.80(2.39)$ \\
$\quad$ Negative items mentioned & $5.56(2.35)$ & $5.50(2.39)$ & $3.20(2.39)$ \\
$\quad$ Statement of attraction & $5.56(3.17)$ & $1.20(1.03)$ & $1.50(2.22)$ \\
$\quad$ Statement of aversion & $2.33(2.18)$ & & $5.07^{\mathrm{b}}(0.47)$ \\
Post-discussion questionnaire: & & $5.95(0.36)$ & $5.17^{\mathrm{b}}(1.36)$ \\
$\quad$ New information & $2.33^{\mathrm{a}}(1.02)$ & $2.70(0.44)$ & $2.62(0.52)$ \\
$\quad$ Agreement with group decision & $5.95(0.37)$ & & $(0.53)$ \\
Post discussion agreement (No. group & $2.56(0.53)$ & & \\
$\quad$ members) & & & \\
\hline
\end{tabular}

Note: Standard deviations are in parentheses. Means not sharing the same superscript differ reliably $(p<.05)$ in a Tukey post-hoc test.

member in favour of refusal, and in four groups one member was in favour of refusal; in the positive bias condition no group member was in favour of the refusal option; in the negative bias condition, there was one group with no member preferring refusal, five groups with one member preferring refusal, three groups with two members preferring refusal, and one group with three members in favour of refusal. These differences were significant, $\chi^{2}(6$, $N=30)=19.84, p=.003$, Cramer's $V=.58$.

Candidate pre-discussion suitability ratings were analysed with a 3 (condition) $\times 3$ (candidate) mixed-model ANOVA, with candidate as a within-participants variable (see Table 3 ). This yielded the expected main effect of condition, $F(2,87)=37.08, p<.001, \eta^{2}=.46$, showing that across candidates ratings were lower in the negative bias condition $(M=3.10)$ than in the full information condition $(M=4.33)$ and the positive bias condition $(M=4.65$; Tukey post-hoc test, both $p<.001)$. The full information and positive bias conditions did not differ $(p=.22)$. There was a marginally significant main effect for candidate, $F(2,86)=2.87, p=.06, \eta^{2}=.06$ $\left(M_{\text {candidate A }}=4.25 ; M_{\mathrm{B}}=3.86 ; M_{\mathrm{C}}=3.97\right)$. There also was an unanticipated interaction between condition and candidate, $F(4,172)=3.93$, $p=.004, \eta^{2}=.08$. The difference between the conditions was significant for candidate A, $F(2$, $87)=36.91, p<.001, \eta^{2}=.46$ and candidate $\mathrm{C}$, $F(2,87)=23.41, p<.001, \eta^{2}=.35$, but not for candidate B, $F(2,87)=1.82, p=.17, \eta^{2}=.04$. In general, however, it can be concluded that participants in the negative bias condition had a less favourable opinion about the candidates, and more often favoured the refusal option. Thus, Hypothesis 1 was confirmed.

\section{Video recordings}

For one group, no video recording was available (due to equipment failure), leaving 29 groups for these analyses. Discussion time was measured using the video recordings, and ANOVA showed no differences between conditions, $F(2,26)=0.59, p=.56, \eta^{2}=.05$ (see Table 2). Further, a distinction was made between positive and negative information that came up during discussion, and information exchange was analysed with a 3 (condition) $\times 2$ (information: positive or negative) mixed-model ANOVA, with the information variable as a within-groups variable. This analysis did not yield significant effects. There was no main effect of information, and on average as many positive $(M=5.97)$ as negative $(M=6.28)$ items of information were mentioned, $F(2,26)=0.47, p=.50, \eta^{2}=.02$. There also was no overall main effect of 
condition, $F(2,26)=1.31, p=.29, \eta^{2}=.09$, and no condition by information interaction, $F(2$, $26)=2.02, p=.15, \eta^{2}=.13$. Thus, although in the positive bias condition positive information was shared and negative information unshared, whereas this was reversed in the negative bias condition, there were no reliable biases in the information that was mentioned during discussion, and Hypothesis 2 should be rejected. Surprisingly, the means were even in the opposite direction (see Table 2), with more negative than positive information being discussed in the positive bias condition, and more positive than negative information discussed in the negative bias condition. This is discussed in the Discussion.

The number of times an attraction or aversion was mentioned was analysed with a 3 (condition) $\times 2$ (statement: attraction or aversion) mixed ANOVA, with statement as a within-groups variable (Table 2 ). This analysis yielded a main effect of statement, $F(1,26)=25.96, p<.001$, $\eta^{2}=.50$, showing that on average more often attractions $(M=4.72)$ than aversions $(M=1.66)$ were expressed. There was a marginally significant effect of condition, $F(2,26)=2.74, p=.08$, $\eta^{2}=.17$. Across attractions and aversions, somewhat more statements were made in the full information condition $(M=3.94)$ than in the negative bias condition $(M=2.35$; Tukey post hoc test, $p=.07)$. The positive bias condition was in between $(M=3.35)$ and did not differ from either of the other conditions. The condition by statement interaction was not significant, $F(2,26)=1.62, p=.22, \eta^{2}=.11$.

Overall, the analyses of the video recordings thus show no large systematic biases in the content of the discussion. Differences among conditions in choice behaviour do therefore not seem to have been caused by biases during discussion.

\section{Group decision and mediation analysis}

Group decision was analysed with a chi-square test of frequencies, which yielded a significant effect of condition, $\chi^{2}(2, N=30)=6.67, p=.04$, Cramer's $V=.47$. In the full information condition $20 \%$ of the groups preferred refusal, in the positive bias condition this was $10 \%$. However, in the negative bias condition $60 \%$ of the groups did not choose any of the candidates (see Table 2 ). This confirms Hypothesis 3.

It is likely that group choices largely reflect pre-discussion preferences of group members. Indeed, the number of group members with a pre-discussion preference for refusal was a significant predictor of group choice, $\chi^{2}(3$, $N=30)=12.07, p=.007$, Cramer's $V=.63$. Two of 17 groups (12\%) without any group member preferring refusal eventually chose to hire none of the candidates. Three of nine groups (33\%) with one member in favour of refusal rejected all three alternatives. All four groups with a majority of two or unanimity in favour of refusal eventually decided not to hire any candidate. It thus appears that group decisions strongly reflect pre-discussion preference distributions.

It was predicted (Hypothesis 4) that there might be two mediators for the effect of condition on group choice: pre-discussion preferences for refusal and a bias during discussion towards negative information. However, because there were significant differences between conditions in the number of group members that preferred refusal before the discussion, but not in the information that was exchanged during the discussion, only pre-discussion preferences qualify as a potential mediator. To test for this, a series of regression analyses were performed (Baron \& Kenny, 1986). Because there were no differences between the complete information and positive bias conditions, these were taken together, and a dummy variable was created comparing these two conditions (coded 0 ) with the negative bias condition (coded 1). In a logistic regression, this dummy variable had a significant effect on group choice, $B=2.14$, $S E=0.90$, Wald $=5.66, p=.02$. A linear regression further yielded a significant effect of this dummy variable on the potential mediator (the number of group members initially favouring refusal), $B=1.20, S E=0.23, t=5.29, p<.001$. Finally, when both the dummy variable and the mediator were regressed on group choice in a logistic regression, the dummy variable no longer had a significant effect, $B=0.29, S E=1.25$, Wald $=0.05$, $p>.80$, whereas the mediator had a significant effect, $B=1.92, S E=0.97$, Wald $=3.89, p<.05$. A 
Sobel test indicated that mediation was (marginally) significant, $Z=1.85, p=.06$. Thus, the effect of condition on group choice was mediated by pre-discussion preferences, and Hypothesis 4 is partially confirmed: only pre-discussion preferences but not information exchange mediated the effect of condition on choice.

\section{Post-discussion questionnaire}

The extent to which new information came up during discussion was measured with two postdiscussion questionnaire items (Table 2). A one-way ANOVA showed a significant effect of condition, $F(2,24)=33.03, p<.001, \eta^{2}=.73$. The full information condition $(M=2.33)$, where each group member had received the same complete set of information and no new information could enter the discussion, differed reliably from both the negative $(M=5.17)$ and the positive bias conditions $(M=6.07$; Tukey post-hoc test, $p<.001)$.

Candidate suitability ratings after the discussion are displayed in Table 3 . These ratings were analysed with a 3 (condition) $\times 3$ (candidate) mixed-model ANOVA. As was the case with the pre-discussion ratings, there was a main effect of condition, $F(2,27)=7.89, p=.002$, $\eta^{2}=.37$. Ratings were lower in the negative bias condition $(M=3.07)$ than in the full information condition $(M=4.16)$ and the positive bias condition $(M=4.31$; both $p<.01$ in a Tukey post-hoc test). There also was a candidate main effect, $F(2,26)=5.52, p=.01, \eta^{2}=.30$, showing that candidate $\mathrm{A}(M=4.24)$ had higher ratings than candidate $\mathrm{B}(M=3.56)$ and candidate $\mathrm{C}$ was in between $(M=3.74)$. The interaction between condition and candidate was marginally significant, $F(4,52)=2.26, p=.08, \eta^{2}=.15$. As was the case with the pre-discussion ratings, the difference between conditions was significant for candidate $\mathrm{A}, F(2,27)=7.30, p=.003, \eta^{2}=.35$, and candidate $\mathrm{C}, F(2,27)=9.54, p=.001$, $\eta^{2}=.41$, but not for candidate $\mathrm{B}, F(2,27)=0.51$, $p=.61, \eta^{2}=.04$.

Because new negative information could only be mentioned in the positive bias condition and new positive information only in the negative bias condition, candidate ratings after discussion might have gone down relative to pre-discussion ratings in the positive bias condition and up in the negative bias condition. Therefore, a 3 (condition) $\times 3$ (candidate) $\times 2$ (time: pre-discussion vs. post-discussion ratings) ANOVA, with the last two variables within groups, was performed. ${ }^{1}$ This analysis showed a marginally significant main effect of time, $F(1,27)=3.70, p=.07, \eta^{2}=.12$. On average, ratings were slightly lower after the discussion (across all candidates $M=3.84$ ) than before the discussion $(M=4.03)$. Importantly, the condition by time interaction was not significant, $F<1, \eta^{2}=.06$, which suggests that discussion did not impact candidate ratings very much. However, there was a marginally significant candidate by time interaction, $F(2$, 26) $=2.97, p=.07, \eta^{2}=.19$, which was further qualified by a marginally significant candidate by time by condition interaction, $F(4,52)=2.10$, $p=.09, \eta^{2}=.14$. As can be seen in Table 3 , ratings in general remained stable or went down slightly (especially in the positive bias condition), except for the ratings of candidate $\mathrm{A}$ in the negative bias condition. These ratings went up slightly.

\begin{tabular}{|c|c|c|c|c|c|c|c|c|c|}
\hline \multirow[b]{3}{*}{ Measure } & \multicolumn{9}{|c|}{ Condition } \\
\hline & \multicolumn{3}{|c|}{ Full information } & \multicolumn{3}{|c|}{ Positive bias } & \multicolumn{3}{|c|}{ Negative bias } \\
\hline & A & B & C & A & B & C & A & B & C \\
\hline Pre-discussion ratings & $\begin{array}{l}4.60 \\
(.61)\end{array}$ & $\begin{array}{l}3.93 \\
(.65)\end{array}$ & $\begin{array}{l}4.46 \\
(.80)\end{array}$ & $\begin{array}{l}5.22 \\
(.78)\end{array}$ & $\begin{array}{l}4.14 \\
(.52)\end{array}$ & $\begin{array}{l}4.59 \\
(.61)\end{array}$ & $\begin{array}{l}2.92 \\
(.61)\end{array}$ & $\begin{array}{c}3.51 \\
(.91)\end{array}$ & $\begin{array}{c}2.86 \\
(.61)\end{array}$ \\
\hline Post-discussion ratings & $\begin{array}{l}4.60 \\
(.55)\end{array}$ & $\begin{array}{l}3.80 \\
(.94)\end{array}$ & $\begin{array}{c}4.08 \\
(1.18)\end{array}$ & $\begin{array}{c}4.90 \\
(1.28)\end{array}$ & $\begin{array}{l}3.53 \\
(.76)\end{array}$ & $\begin{array}{l}4.50 \\
(.93)\end{array}$ & $\begin{array}{c}3.23 \\
(1.14)\end{array}$ & $\begin{array}{c}3.33 \\
(1.33)\end{array}$ & $\begin{array}{c}2.63 \\
(.86)\end{array}$ \\
\hline
\end{tabular}

Note: Standard deviations are in parentheses. A, B and C refer to candidates. 
It thus seems that new information brought up during discussion has had some impact on candidate ratings, but not much.

Agreement with the decision did not differ reliably across conditions. First, based on the postdiscussion questionnaires, I counted the number of group members that had the same postdiscussion preference as the group decision, and this did not differ across conditions, $F<1$, $\eta^{2}=.04$. Most group members agreed with the decision (on average 2.65 of 3 group members had the same preference). I also analysed the ratings of decision agreement, and found no effect either, $F<1, \eta^{2}=.04$. Agreement was quite high ( $M=6.01$ on a 7 -point scale).

\section{Additional analyses}

The results thus far suggest that group choice was largely determined by pre-discussion preferences. Further, the new information that did come up during the discussion (in the positive and negative bias conditions) did not have much impact on choice. To further investigate the latter (lack of) effects, I looked at correlations between the process data (the sharing of information and attractions/aversions) and choice and postdiscussion candidate ratings.

The findings were consistent with the general picture (see Table 4). The exchange of information about particular candidates was not associated with choice (choice was dummy coded with 0 , refusal and 1 , choice), all $-.26<r<.24$ (all $p>.15$ ). Further, post-discussion candidate ratings also were not strongly associated with the information exchanged about these candidates. There only was one significant correlation, which (surprisingly) was a positive correlation between the number of negative items of information exchanged about candidate $\mathrm{C}$ and ratings of $\mathrm{C}$. Should this negative information have had any impact, the correlation should at least have been negative. However, as can be seen in Table 4, the exchange of attractions for a particular candidate was consistently associated with the ratings of that candidate $(.53<r<.65, p<.01)$. Further, only the exchange of attractions for candidate A was correlated with choice $(r=.42$, $p=.02)$.

\section{Discussion}

Although many researchers have studied group decision making, the topic of group decisions that do not get made (with the exception of hung juries) has largely been ignored. In the present study, the effects of pre-discussion preferences and opinions on group decision refusal were investigated. Group decision refusal occurs when the group refuses to take any of the presently available options, but instead opts to

Table 4. Correlations between process data and group decision and post-discussion candidate ratings $(N=29$ groups $)$

\begin{tabular}{|c|c|c|c|c|}
\hline $\begin{array}{l}\text { Information/preference } \\
\text { exchange }\end{array}$ & $\begin{array}{c}\text { Choice } \\
(1=\text { choice })\end{array}$ & $\begin{array}{c}\text { Ratings of } \\
\text { candidate A }\end{array}$ & $\begin{array}{c}\text { Ratings of } \\
\text { candidate B }\end{array}$ & $\begin{array}{c}\text { Ratings of } \\
\text { candidate } \mathrm{C}\end{array}$ \\
\hline Positive info A & .24 & .18 & -.26 & .16 \\
\hline Negative info A & .21 & .10 & -.10 & .31 \\
\hline Positive info B & -.13 & $-.35 \dagger$ & .10 & -.12 \\
\hline Negative info B & .05 & -.12 & .09 & -.07 \\
\hline Positive info $\mathrm{C}$ & -.26 & -.09 & -.25 & .19 \\
\hline Negative info $\mathrm{C}$ & .24 & .26 & .28 & $.48 * *$ \\
\hline Attraction for A & $.42 *$ & $.65 * * *$ & .14 & $.33 \dagger$ \\
\hline Aversion against A & -.20 & $-.34 \dagger$ & -.18 & -.15 \\
\hline Attraction for B & -.01 & -.29 & $.56 * *$ & -.15 \\
\hline Aversion against $B$ & .22 & .17 & -.15 & $.43^{*}$ \\
\hline Attraction for C & .09 & -.04 & -.16 & $.54 * *$ \\
\hline Aversion against $\mathrm{C}$ & .16 & .08 & $.33 \dagger$ & $-.31 \dagger$ \\
\hline
\end{tabular}

Note: $\dagger p<.10 ; * p<.05 ; * * p<.01 ; * * * p<.001$. For clarity, correlations between process data and corresponding candidate ratings are bold. 
invest further resources to identify more options. Three conditions were created, differing in the way information was distributed among group members, to manipulate pre-discussion opinions towards decision alternatives. Specifically, a full information condition was compared with a positive bias condition (positive information was given to all group members, negative information was distributed among the members) and a negative bias condition (negative information was given to all members, positive information was distributed among the members).

The main finding from this experiment is that when group members enter a discussion with a negative view on all available options (job candidates, in this case), the group is likely not to select any of them, even if information is present that would suggest that the options are not as bad as they first seemed. Thus, most groups $(80 \%)$ in the full information condition did make a choice, indicating that on the whole the candidates were perceived to be adequate. However, groups in the negative bias condition were not very likely to adjust their initial negative views, and therefore remained rather negative and often $(60 \%)$ decided against all candidates.

The negative view of all candidates in the negative bias condition persisted despite the fact that, according to both the self-reports and the analysis of video recordings, new information came up during discussion. As new information in that condition was always positive, it should have led to an increase in candidate ratings. However, this new information did not affect group member's liking of the options much and had no relation with group choice. Therefore, the negative opinions persisted and pre-discussion preferences in favour of refusal could explain the effects of condition on group choice. This finding is consistent with the common knowledge effect (Gigone \& Hastie, 1993, 1997): shared negative information in the negative bias condition had more impact on choice than unshared positive information because: (i) it had more impact on pre-discussion preferences, and (ii) it led to a biased evaluation of new (positive) information.
Correlational analyses further showed that information exchange in general was not associated with choice or post-discussion ratings of the candidates. However, the exchange of preferences was: the number of times a statement was made in favour of a particular candidate was positively correlated with the ratings for that candidate. This further corroborates the idea that choice was largely based on the pooling of preferences, rather than on the systematic consideration of information. Related to this, Hastie, Penrod, and Pennington (1983), in the context of jury decision making, suggested the distinction between 'verdict-driven' and 'evidence-driven' jury decision strategies. A verdict-driven strategy (or more generally: a 'preference-driven' strategy) implies frequent polling and decisions based on initial group member preferences, while an 'evidence-driven' strategy (or 'information-driven' strategies) implies the exchange and elaboration of decision-relevant information and a decision based upon the available information (also De Dreu, Nijstad, \& van Knippenberg, 2008; Stasser \& Birchmeier, 2003). Groups in this study can clearly be characterized as 'preference driven' rather than 'information driven'. Further, a preference-driven strategy was maladaptive, because it prevented groups from discovering that the candidates were not as bad as initially believed.

Surprisingly, no evidence was found for a systematic bias in the information that was exchanged. Thus, unlike has been found in much previous work (Larson et al., 1994; Stasser \& Titus, 1985), there was no evidence for shared information (positive information in the positive bias condition, negative information in the negative bias condition) to be discussed more than unshared information. Partly, I suspect, this is due to the relatively few items of information that were used (six items per candidate), as it has previously been shown that the bias is stronger when information load is higher (Stasser \& Titus, 1987). In another study with the same paradigm (Nijstad \& Kaps, 2008), a bias in information sharing with a higher information load (eight items per candidate) was found. It might also be 
possible that adding a refusal option to the choice set changes the normal discussion patterns. For example, in the negative bias condition group members will have considered the refusal option and might have tried to argue against that, using (unshared) positive information.

\section{Implications, limitations and future directions}

To date, the work on group indecision (i.e. cases in which groups do not reach a decision) has mostly been limited to work on hung juries. In that literature, almost by definition, opinion diversity (i.e. jurors who favour guilty as well as jurors who favour not guilty) is an important determinant of the failure to reach a verdict. More particularly, if jurors hold different opinions, and they do not give in, the jury might be hung (also see Nijstad \& Kaps, 2008). Here, another determinant was identified: initial negative opinions about the different alternatives.

The finding that initial negative opinions persist despite positive information becoming available during discussion, and that this might lead the group to refuse all available alternatives, potentially has some important implications. Although I am not aware of any systematic research on this topic, common experience suggests that groups often fail to commit themselves to a particular alternative. When several or even all group members (as in the present study) are relatively negative about currently available alternatives, and there is no real pressure to come to a decision, this, according to the present findings, is a likely result. Groups will perhaps even refuse to choose when only one or a few members are negative about all options. When groups strive for unanimity, even a small minority of group members might veto all decisions, which would lead to decision refusal. Indeed, I found that in about one-third of the groups in which one of three members initially favoured decision refusal no choice was made. As noted earlier, this is not necessarily maladaptive (e.g. bad decision options should be refused), but it can lead to real costs when a decision should be made quickly or when adequate alternatives are rejected.
Related to that last point, an important limitation of the present study should be noted. Group choice had no real implications for group members. Thus, although it was emphasized that refusal in real life is costly, groups could refuse all options without their choice negatively affecting any real outcomes. However, this was true for all conditions, so differences among conditions cannot be attributed to this. Furthermore, in real life many decisions might not necessarily be costly for the people taking them (e.g. the selection committee), but rather for the organizations as a whole. Although these considerations suggest that the present results may generalize to real life situations, it is nevertheless important to establish whether the present findings extend to choices that do have real consequences.

Another limitation of the present study relates to sample size. With only 10 groups in each condition some effects might have failed to reach conventional levels of significance because of lack of statistical power. In particular, the results regarding information exchange, the exchange of preferences and discussion time might have been stronger with a larger sample size. However, as group choice was mainly driven by pre-discussion preferences, I do not expect qualitatively different results with a larger sample.

Several other issues might be interesting to pursue. For example, the no choice option in this experiment was to refuse all alternatives and look for more options. It might be the case that this type of no choice has other determinants than other types of no choice, such as delaying a decision in order to search for more information about available alternatives (rather than looking for new ones). For example, search for more information might be the preferred option when current alternatives are close in attractiveness, and it is difficult to choose among them (cf. Tversky \& Shafir, 1992; Dhar, 1997). Future work may study this in a group context.

Other interesting issues might be to study factors that we know have an impact on group decision making, including leadership (Larson, Foster-Fishman, \& Franz, 1998), time pressure (Kelly \& Loving, 2004) and explicit decision rules (i.e. unanimity required; Stasson, Kameda, Parks, Zimmerman, \& Davis, 1991; also Kerr \& 
MacCoun, 1985). Some of these factors may increase or decrease the group's reliance on preference- versus information-driven interaction (also see De Dreu et al., 2008). For example, time pressure leads to shorter discussion, and perhaps to more preference-driven decision strategies, as this is a quick way to come to a decision. However, effective leaders might stimulate information elaboration, and thus lead to more information-driven decision strategies. In a context in which a preferencedriven interaction may lead to decision refusal, such as in the present study, leadership might reduce refusal, whereas time pressure might increase it.

\section{Conclusion}

All in all, this study suggests that initial negative views about decision options might not easily be corrected when other group members provide new positive information during discussion. Rather, this information is evaluated in a biased way, and group members remain negative about the options. In turn, when this is possible, it often leads groups to refuse all options, even though as a whole the options may be adequate. Therefore, the present research extends findings on the common knowledge effect-the effect that shared information has more impact on group choice than unshared information-by showing that under certain conditions this bias may lead groups to not decide at all.

\section{Note}

1. There also was a main effect of condition, $F(2,27)=16.78, p<.001$, a main effect of candidate, $F(2,26)=4.54, p=.02$, and a candidate by condition interaction, $F(4,52)=2.83, p=.03$. These have already been discussed in the descriptions of the univariate ANOVAs.

\section{Acknowledgements}

This research was financially supported by a grant from the Netherlands Organization of Scientific Research (NWO, grant 452-04-311). Parts of the present research were presented at the Annual meetings of the Society of Experimental Social Psychology (San Diego, October, 2005) and at the meetings of the European Association of Experimental Social Psychology (Würtzburg, Germany, July 2005).

\section{References}

Anderson, C. J. (2003). The psychology of doing nothing: Forms of decision avoidance result from reason and emotion. Psychological Bulletin, 129, 139-167.

Baron, R. M., \& Kenny, D. A. (1986). The moderator-mediator variable distinction in social psychological research: Conceptual, strategic and statistical considerations.

Journal of Personality and Social Psychology, 51, 1173-1182.

Corbin, R. M. (1980). Decisions that might not get made. In T. S. Wallsten (Ed.), Cognitive processes in choice and decision behaviour (pp. 47-67). Hillsdale, NJ: Erlbaum.

Davis, J. H. (1973). Group decision and social interaction: A theory of social decision schemes. Psychological Review, 80, 97-125.

De Dreu, C. K. W., Nijstad, B. A., \& Van Knippenberg, D. (2008). Motivated information processing in group judgment and decision making. Personality and Social Psychology Review, 12, 22-49.

Dhar, R. (1996). The effect of decision strategy on the decision to defer choice. Journal of Behavioral Decision Making, 9, 265-281.

Dhar, R. (1997). Consumer preference for a no-choice option. Journal of Consumer Research, 24, 215-231.

Gigone, D., \& Hastie, R. (1993). The common knowledge effect: Information sharing and group judgment. Journal of Personality and Social Psychology, 65, 959-974.

Gigone, D., \& Hastie, R. (1997). The impact of information on small group choice. Journal of Personality and Social Psychology, 72, 132-140.

Greitemeyer, T., \& Schulz-Hardt, S. (2003). Preference-consistent evaluation of information in the hidden profile paradigm: Beyond group level explanations for the dominance of shared information in group decisions. Journal of Personality and Social Psychology, 84, 322-339.

Hastie, R., Penrod, S. D., \& Pennington, N. (1983). Inside the jury. Cambridge, MA: Harvard University Press.

Kelly, J. R., \& Loving, T. J. (2004). Time pressure and group performance: Exploring the 
underlying processes in the Attentional Focus Model. Journal of Experimental Social Psychology, 40, 185-198.

Kerr, N. L., \& MacCoun, R. J. (1985). The effects of jury size and polling method on the process and product of jury deliberation. Journal of Personality and Social Psychology, 48, 349-363.

Kerr, N. L., \& Tindale, R. S. (2004). Group performance and decision making. Annual Review of Psychology, 55, 2201-2232.

Larson, J. R., Foster-Fishman, P. G., \& Franz, T. M. (1998). Leadership style and the discussion of shared and unshared information in decision making groups. Personality and Social Psychology Bulletin, 24, 482-495.

Larson, J. R., Foster-Fishman, P. G., \& Keys, C. B. (1994). Discussion of shared and unshared information in decision-making groups. Journal of Personality and Social Psychology, 67, 446-461.

Nijstad, B. A., \& Kaps, S. C. (2008). Taking the easy way out: Preference diversity, decision strategies, and decision refusal in groups. Journal of Personality and Social Psychology, 94, 860-870.

Postmes, T., Spears, R., \& Cihangir, S. (2001). Quality of decision making and group norms. Journal of Personality and Social Psychology, 80, 918-930.

Stasser, G. (1999). A primer of social decision scheme theory: Models of group influence, competitive model testing, and prospective modeling. Organizational Behavior and Human Decision Processes, 80, 3-20.

Stasser, G., \& Birchmeier, Z. (2003). Group creativity and collective choice. In P. B. Paulus \& B. A. Nijstad (Eds.), Group creativity: Innovation through collaboration (pp. 85-109). New York: Oxford University Press.
Stasser, G., Taylor, L. A., \& Hanna, C. (1989). Information sampling in structured discussions of three- and six-person groups. Journal of Personality and Social Psychology, 57, 67-78.

Stasser, G., \& Titus, W. (1985). Pooling of unshared information in group decision making: Biased information sampling during discussion. Journal of Personality and Social Psychology, 48, 1467-1478.

Stasser, G., \& Titus, W. (1987). Effects of information load and percentage of shared information on the dissemination of unshared information during group discussion. Journal of Personality and Social Psychology, 53, 81-93.

Stasson, M. F., Kameda, T., Parks, C. D., Zimmerman, S. K., \& Davis, J. H. (1991). Effects of assigned group consensus requirement on group problem solving and group member learning. Social Psychology Quarterly, 54, 25-35.

Tversky, A., \& Shafir, E. (1992). Choice under conflict: The dynamics of deferred decision. Psychological Science, 3, 358-361.

Vroom, V. H., \& Yetton, P. W. (1973). Leadership and decision making. Pittsburgh, PA: Pittsburgh University Press.

Paper received 9 November 2006; revised version accepted 9 November 2007.

\section{Biographical note}

BERNARD A. NIJSTAD received his BA from Utrecht University in 1995 and his $\mathrm{PhD}$ from that same university in 2000. He is currently an associate professor of organizational psychology at the University of Amsterdam. His research interests include decision making and indecision, and creativity and innovation. 